\title{
FLOATING GASTRORETENTIVE OF AMOXICILLIN USING HARD ALGINATE CAPSULES AND ITS ANTIBACTERIAL ACTIVITIES
}

\author{
ANAYANTI ARIANTO, HAKIM BANGUN*, ADE YOHANA, JANSEN SILALAHI \\ Department of Pharmaceutical Technology, Faculty of Pharmacy, Nanomedicine Centre, University of Sumatera Utara, Indonesia. \\ Email: Hakimb17@yahoo.com
}

Received: 03 February 2017, Revised and Accepted: 27 February 2017

ABSTRACT

Objective: The aim of this study was to formulate the floating gastroretentive of amoxicillin using hard alginate capsules shell and evaluate the antibacterial activities of floating gastroretentive of amoxicillin.

Methods: Amoxicillin was prepared in the solid dispersion form, it was prepared by a solvent method using polyvinylpyrrolidone (PVP) K30. The solid dispersion was characterized by X-ray diffraction and Fourier transformed infra-red analysis. The drug was filled into alginate capsule shell. Drug release test was carried out using USP paddle method in simulated gastric fluid. Concentrations of amoxicillin were determined using spectrophotometer ultraviolet at wavelength of $272 \mathrm{~nm}$. The antibacterial activity of aliquots dissolution was assessed using agar plate diffusion method against Staphylococcus aureus and Escherichia coli as bacterial model

Results: The dissolution test results showed that amoxicillin in the solid dispersions form with a weight ratio of amoxicillin and PVP K30 was 1:1 caused sustained release of amoxicillin for $12 \mathrm{hrs}$, while the release of amoxicillin without solid dispersion was too slow. The floating lag time was 0 minute and floating time was more than $12 \mathrm{hrs}$. The X-ray diffraction pattern of amoxicillin solid dispersion had amorphous shape. Antibacterial activity test showed that the dissolution aliquots of amoxicillin solid dispersion were effective against $S$. aureus and $E$. coli.

Conclusions: Based on the results of this study, it is concluded that the alginate capsules shell can be used for the preparation of floating gastroretentive of amoxicillin using amoxicillin solid dispersion and the dissolution aliquots give antibacterial effect.

Keywords: Floating, Gastroretentive, Alginate capsule, Amoxicillin, Solid dispersion, Release, Antibacterial.

(C) 2017 The Authors. Published by Innovare Academic Sciences Pvt Ltd. This is an open access article under the CC BY license (http://creativecommons. org/licenses/by/4. 0/) DOI: http://dx.doi.org/10.22159/ajpcr.2017.v10i5.17467

\section{INTRODUCTION}

Helicobacter pylori is believed to be the main cause of peptic ulcer due to an imbalance between aggressive factors (H. pylori, nonsteroidal antiinflammatory drugs [NSAIDs], and gastric acid) and defensive factors (mucin, bicarbonate, and prostaglandins), leading to disturbances in the mucosal tissue [1]. The prevalence of peptic ulcers in developed countries is $30-40 \%$, while in developing countries is $80-90 \%$. As many as $48 \%$ of patients with peptic ulcers are caused by $H$. pylori infection and $24 \%$ due to the use of NSAID drugs [2]

Amoxicillin is a beta-lactam antibacterial, which has a broad-spectrum activity against different types of infections caused by both Grampositive and Gram-negative bacteria, including $H$. pylori by inhibiting the process of cell wall synthesis [3]. Clinical studies using amoxicillin show that amoxicillin is the least resistant compared to clarithromycin or metronidazole against $H$. pylori [4], but amoxicillin is ineffective even at high dose when it is administered in conventional oral dosage form because the limited contact time [5]. The contact time of antibacterial drug with organism should be long enough to be able to achieve successful eradication of $H$. pylori from gastric mucosa. Hence, a suitable pharmaceutical dosage form for $H$. pylori eradication is also an important basic principle of the drug delivery system dominating these constraints and offering a proper delivery strategy [6].

Several approaches of dosage formulations with gastroretentive system have been developed to achieve a controlled release of amoxicillin to stay longer in the stomach $[7,8]$. Floating system is a novel approach toward gastroretentive drug delivery systems [9]. One of them is floating drug delivery system or hydrodynamic system, a system that is controlled by the density of pharmaceutical dosage form that can float on gastric fluid and the drug is slowly released on the desired level [10]. In the previous study, it was reported that the formulation tablets of amoxicillin and metronidazole in swellable effervescent floating tablets were carried out as single and double layer tablets using polyethylene glycol and hydroxypropyl methylcellulose polymers [11].

Sodium alginate is a nontoxic polysaccharide that is derived from seaweed (brown algae) [12]. Alginate can be used for the preparation of periodontal drug delivery system and gastroretentive drug delivery system of antacids [13-15]. In the previous study [16], it was reported the preparation and the characterization of hard alginate capsules shell, and it was found that alginate capsules' shell was resistant or did not disintegrate in artificial gastric fluid $(\mathrm{pH} 1.2)$, but it swelled and disintegrated in artificial intestinal fluid ( $\mathrm{pH} 4.5$ and $\mathrm{pH} 6.8)$.

In this paper, it will be discussed the application of alginate capsules shell as floating gastroretentive capsules, and amoxicillin was used as a drug model. Amoxicillin was prepared in the solid dispersion form. The lag and floating time, drug release, antibacterial activity, and the characterization of amoxicillin solid dispersion will be discussed.

\section{MATERIALS AND METHODS}

\section{Materials}

Amoxicillin was obtained from PT. Mutifa, calcium chloride dihydrate, ethanol, and $\mathrm{HCl}$ were product of Merck. Sodium alginate 80-120 cP (Wako pure chemical industries, Ltd. Japan), polyvinylpyrrolidone (PVP) K30 (Nacalai tesque). Hard alginate capsules shell (size 0) was obtained from Laboratory of Physical Pharmacy, Faculty of Pharmacy, University of Sumatera Utara. 


\section{Methods}

Preparation of amoxicillin solid dispersion

Solid dispersion of amoxicillin was prepared by solvent method with various weight ratio of amoxicillin to PVP K30 by dissolving amoxicillin, and PVP 30 in alcohol and the solvent was then evaporated at $40-50^{\circ} \mathrm{C}$ until constant weight, stored for $24 \mathrm{hrs}$ in desiccator. Scraped and crushed and sieved using a sieve no. 12 .

\section{Drug release}

The drug release test was performed using paddle method $(100 \mathrm{rpm})$ in simulated gastric fluid $(\mathrm{pH} 1.2)$ at $37 \pm 0.5^{\circ} \mathrm{C}$. The capsules contained $500 \mathrm{mg}$ amoxicillin or amoxicillin solid dispersion equivalent to $500 \mathrm{mg}$ amoxicillin. In amoxicillin solid dispersion was used two capsules of each capsule containing amoxicillin solid dispersion equivalent to $250 \mathrm{mg}$ amoxicillin. Drug concentrations were measured by ultraviolet spectrophotometer at a wavelength of $272 \mathrm{~nm}(\mathrm{n}=3)$.

\section{Fourier transformed infra-red spectroscopy (FTIR)}

IR spectra were obtained using Shimadzu IR Prestige-21 spectrometer The pulverized samples were micronized with $\mathrm{KBr}$ powder and measured in the range of $4000-400 / \mathrm{cm}$.

\section{X-ray diffraction analysis pattern}

The physicochemical properties of the solid dispersions were investigated with X-ray diffraction (Shimadzu) using the source from $\mathrm{Cu}$ radiation. Observations were made on $2 \theta$, and the scanning speed was 0.8000 per second.

\section{Antibacterial activities assessment}

The antibacterial activity of amoxicillin solid dispersion was performed by agar plate diffusion method. First, the different dilution of standard was prepared in simulated gastric fluid ( $\mathrm{pH}$ 1.2) with a concentration of $0-200 \mu \mathrm{g} / \mathrm{mL}$. Then, the aliquots were taken from dissolution experiment at $0,0.5,1,2,3,4,5,6,7,8,9,10,11$, and $12 \mathrm{hrs}$.

dissolution aliquot was measured with a calliper in mm scale. The minimum inhibitory concentration (MIC) of amoxicillin was calculated using the following equation [7].

$\ln (\mathrm{MIC})=\ln (\mathrm{C})-\frac{\mathrm{x}^{2}}{}$

\section{RESULTS AND DISCUSSIONS}

\section{Floating lag time, floating time, and drug release}

Floating lag time of hard alginate capsule containing amoxicillin was 0 minute, it means that when capsule was immersed in simulated gastric fluid $\mathrm{pH} 1.2$, it floated immediately. The capsules floated during drug release experiment for $12 \mathrm{hrs}$ as shown in Fig. 1. Capsules floated was due to the air entrapped inside of the alginate capsules shell and the density of alginate capsules shell was lower than the density of simulated gastric fluid.

The release of amoxicillin from floating hard alginate capsule is shown in Fig. 2.

The release of pure amoxicillin from hard alginate capsules was too slow as sustained release dosage form for $12 \mathrm{hrs}$ dose interval and did not meet the requirement of sustained release dosage form. The requirement of sustained release dosage form is shown Table 1 [17]. Therefore, to increase the release of amoxicillin, amoxicillin was prepared in solid dispersion form. The release of amoxicillin from hard alginate capsules increased significantly in the solid dispersion form as shown in Fig. 2. In this case, the release of amoxicillin in the solid dispersion form fulfilled the requirement of sustained release dosage form for $12 \mathrm{hrs}$ dose interval.

In amoxicillin solid dispersion form, the dissolution rate of amoxicillin increased because PVP is a water-soluble polymer that enhances the wetting process of amoxicillin. In addition, the modification of amoxicillin to amoxicillin solid dispersion form reduces the particle size of amoxicillin so that the rate of dissolution increased.

Hard alginate capsule shell which was placed in artificial gastric fluid $(\mathrm{pH}$ 1.2) remained in intact condition during drug release. This is

Table 1: The requirement of drug release for sustained release products

\begin{tabular}{llll}
\hline $\begin{array}{l}\text { Administration } \\
\text { interval }\end{array}$ & $\begin{array}{l}\text { Time } \\
\text { (hrs) }\end{array}$ & $\begin{array}{l}\text { Amount } \\
\text { released (\%) }\end{array}$ & Requirements [17] \\
\hline $0.25 \mathrm{D}$ & 3 & 24.84 & $20-50$ \\
$0.5 \mathrm{D}$ & 6 & 50.65 & $45-75$ \\
1 D & 12 & 90.80 & $\geq 75$ \\
\hline
\end{tabular}

D: Dosing interval (12 hrs)

Table 2: The comparison of $\mathbf{R}^{2}$ values on the plots of zero-order, first-order, and Higuchi model drug release

\begin{tabular}{lll}
\hline Kinetic order & Linear equation & $\mathbf{R}^{\mathbf{2}}$ \\
\hline Zero-order & $\mathrm{y}=0.133 \mathrm{x}+0.505$ & 0.994 \\
One order & $\mathrm{y}=0.002 \mathrm{x}+0.525$ & 0.698 \\
Higuchi model & $\mathrm{y}=3.994 \mathrm{x}-21.69$ & 0.966 \\
\hline
\end{tabular}

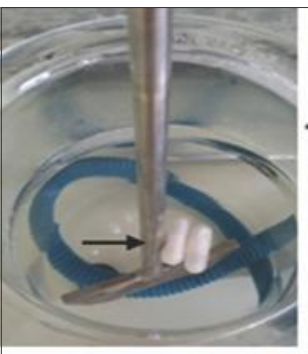

Initial

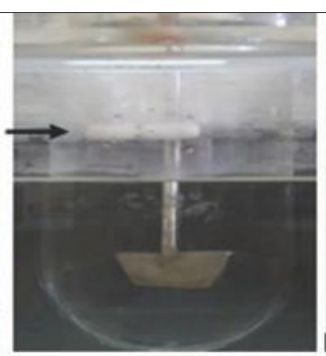

240 minutes

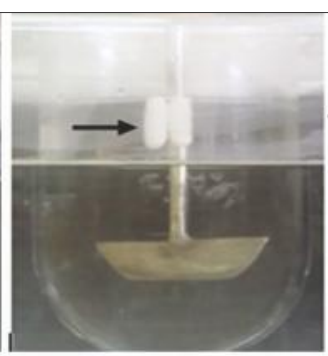

480 minutes

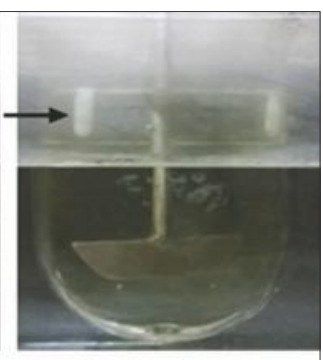

720 minutes

Fig. 1: Floating of hard alginate capsule containing amoxicillin during drug release experiment in simulated gastric fluid at $37^{\circ} \mathrm{C}$. Arrow shows the floating capsules 
caused by the content of alginate capsules $47.5 \%$ is calcium guluronate that is insoluble in simulated gastric fluid $(\mathrm{pH} 1.2)$ [18]. Hard alginate capsules disintegrate in the small intestine. Therefore, hard alginate capsules can be used as floating gastroretentive drug delivery system.

\section{Drug release kinetics}

The drug-release data were analyzed to determine the drug release kinetic. The kinetic release of amoxicillin solid dispersion from alginate capsules shell was determined for zero-order, first-order, and Higuchi model. The comparison of the correlation coefficient $\left(\mathrm{R}^{2}\right)$ of amoxicillin release on the plot of zero-order, first-order, and Higuchi model drug release is presented in Table 2, and the plot for zero-order is shown in Fig. 3. The plot of cumulative of drug released (\%) versus time gives a straight line with the value of $\mathrm{R}^{2}$ is closer to one (0.994) compared to the

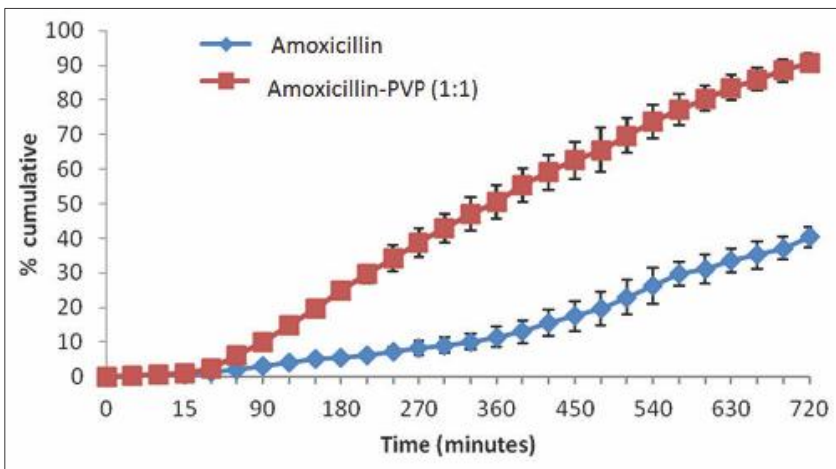

Fig. 2: Release of amoxicillin from floating hard alginate capsules containing amoxicillin and amoxicillin solid dispersion in simulated gastric fluid $(\mathrm{pH} 1.2)$ at $37^{\circ} \mathrm{C}$ for $12 \mathrm{hrs}$

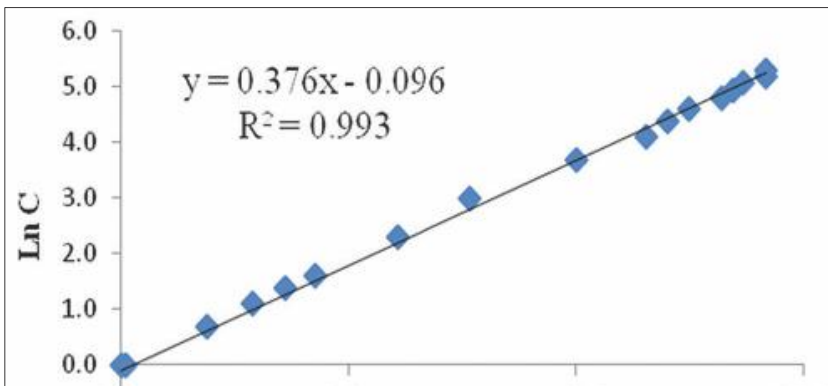

Fig $\mathrm{BDA}$ Zero-order plot of amoxicillin release from floating thard alginate capsules shell in the medî̀im of simulated gastric fluid $(\mathrm{pH} 1.2)$ at $3^{\circ} \mathrm{C}$
$\mathrm{R}^{2}$ of other orders. It means that the release of amoxicillin from alginate capsule follows zero-order release.

\section{FTIR analysis}

The FTIR spectrum results of amoxicillin showed that the absorption band of $\mathrm{O}-\mathrm{H}$ stretching vibration at $3525 / \mathrm{cm}$, but the $\mathrm{O}-\mathrm{H}$ stretching vibration at $3525 / \mathrm{cm}$ of solid dispersion was disappeared (Fig. 4). Therefore, amoxicillin solid dispersion shows an interaction as the intermolecular hydrogen bond between amoxicillin and PVP K-30.

\section{X-ray analysis}

Diffractogram of pure amoxicillin showed crystalline shape (Fig. 5a), but PVP showed amorphous shape (Fig. 5b). Diffractogram of solid dispersion of amoxicillin-PVP (1:1) was the same with pure PVP, it was an amorphous shape (Fig. 5c). X-ray diffraction analysis shows that the change of amoxicillin's crystal structure is caused by the formation of hydrogen bonds between molecules of amoxicillin and PVP as verified by FTIR analysis (Fig. 4). A similar behavior is observed for curcumin solid dispersion with PVP K-30 [19].

\section{Scanning electron microscopy (SEM)}

SEM analysis shows that the surface of alginate capsule shell 80-120 cP is different between before and after dissolution for $12 \mathrm{hrs}$ as shown in Fig. 6. After the dissolution test, the surfaces of capsule shows have many pores.

\section{Antibacterial activities}

The photographs of antibacterial activity test of amoxicillin standard solution with a concentration of $0-200 \mu \mathrm{g} / \mathrm{ml}$ on the growth of $S$. aureus and E. coli using agar plate diffusion method are shown in Figs. 7 and 8 and the data experiment of amoxicillin standard solution is listed in Table 3. The ZOI increased with increasing antibiotic concentrations.

\section{Determination of MIC of amoxicillin}

Equation (1) as shown previously is revealed to be:

$$
\ln (\mathrm{C})=\ln (\mathrm{MIC})+\frac{\mathrm{x}^{2}}{4 \mathrm{Dt}}
$$

From Equation (2), the plot of $\ln C$ versus $x^{2}$ is made and is obtained a straight line as shown in Figs. 9 and 10. The intercept of the line equation is $\mathrm{ln}$ MIC, then the value of MIC of a standard solution of amoxicillin is obtained.

Plots on Figs. 9 and 10 give straight line and the correlation coefficient $\left(\mathrm{R}^{2}\right)$ are 0.990 and 0.993 (good linearity relationship). Values of intercept from the equation, ln MIC is -0.018 and -0.096 ; therefore, the MIC values of amoxicillin against $S$. aureus and $E$. coli are $0.982 \mu \mathrm{g} / \mathrm{mL}$ and $0.909 \mu \mathrm{g} / \mathrm{mL}$, respectively.

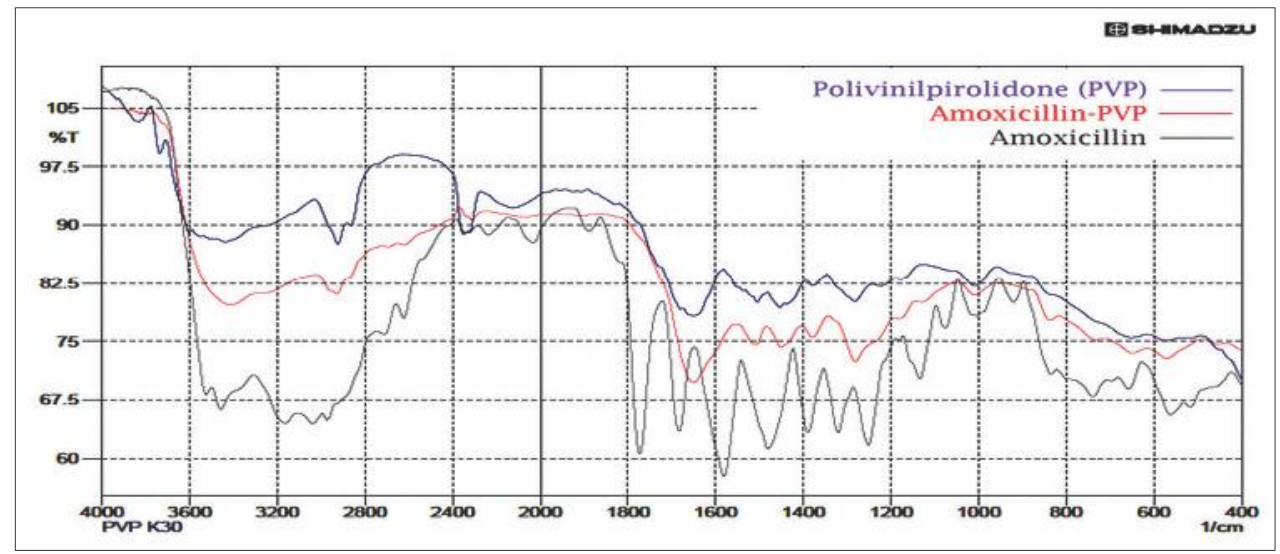

Fig. 4: Infrared spectrograms of amoxicillin as pure chemical and as solid dispersion (amoxicillin-polyvinylpyrrolidone [PVP]), and PVP only 


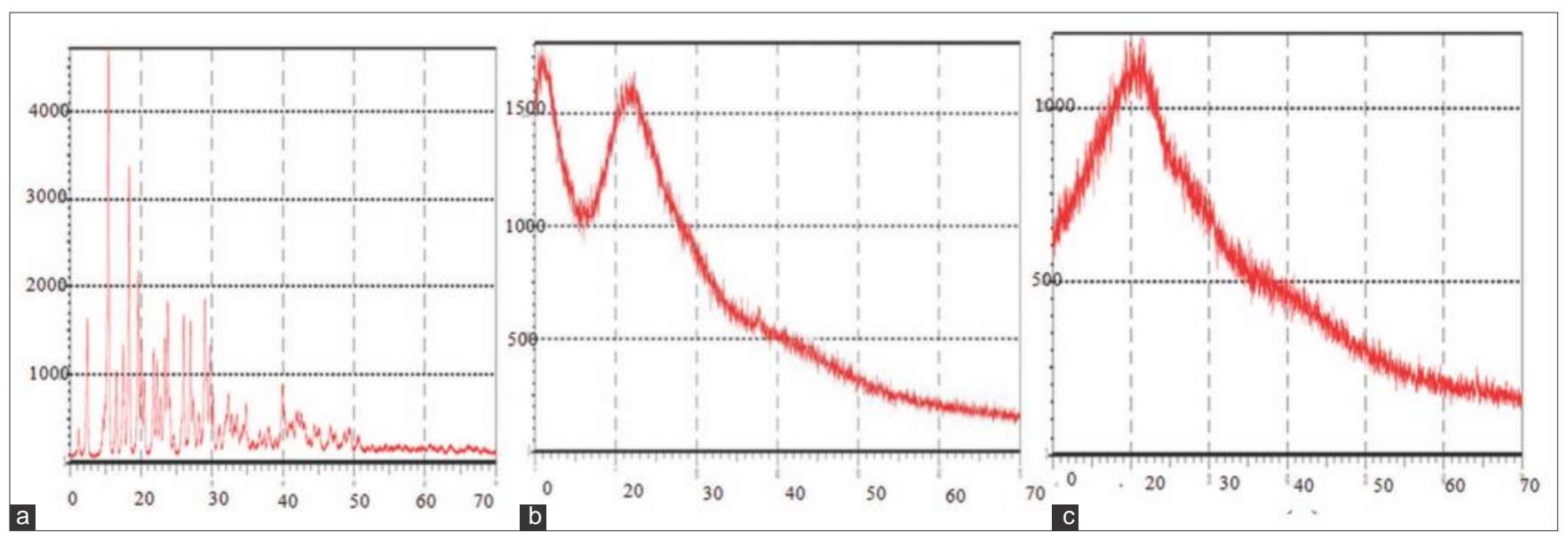

Fig. 5: Diffractograms of amoxicillin (a), polyvinylpyrrolidone (PVP) (b), and solid dispersion amoxicillin-PVP(c)

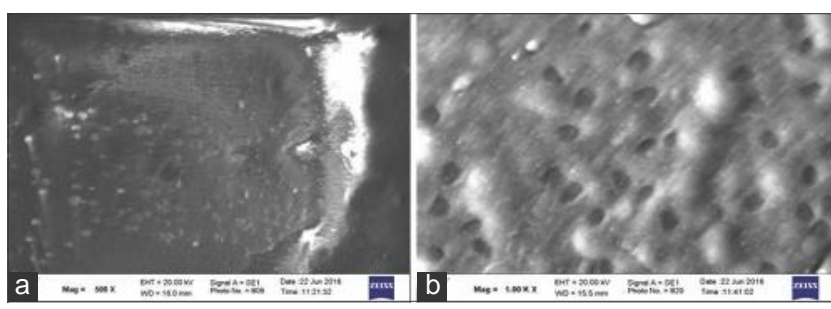

Fig. 6: Scanning electron microscopy of alginate capsule shell. (a) initial and (b) after drug release experiment
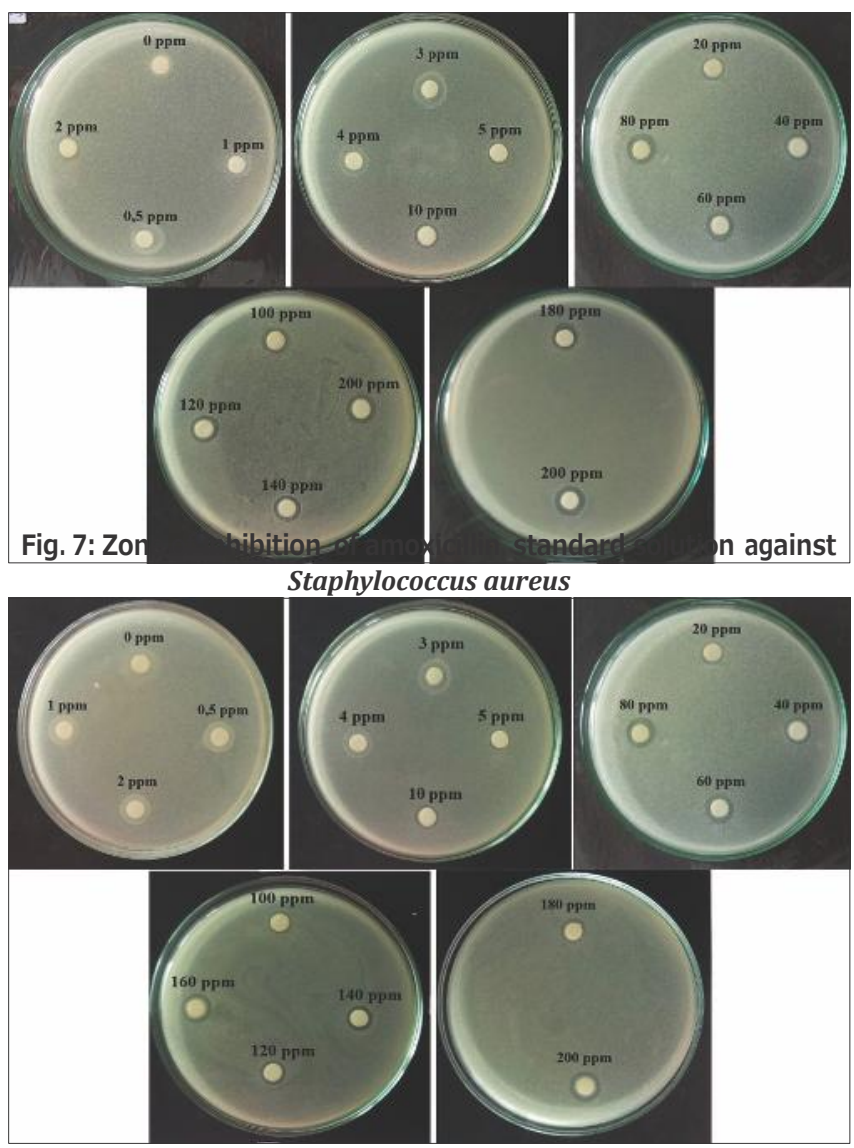

Fig. 8: Zone of inhibition of amoxicillin standard solution against Escherichia coli

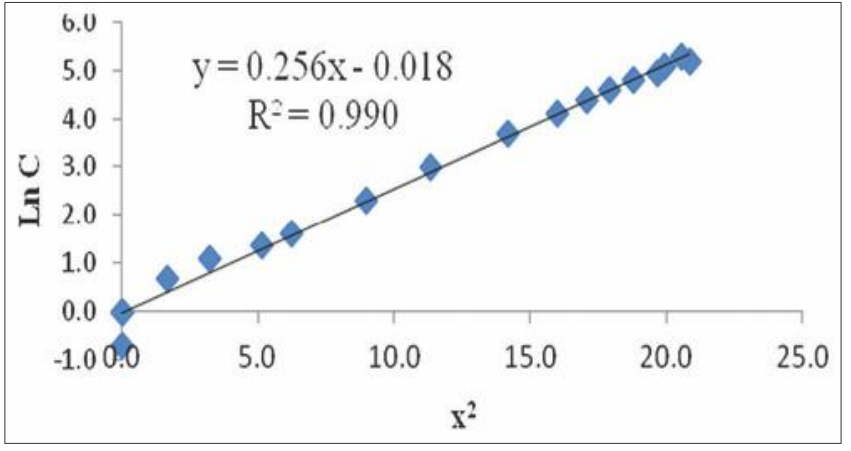

Fig. 9: Plot In C versus $\mathrm{x}^{2}$ of amoxicillin standard solution against Staphylococcus aureus

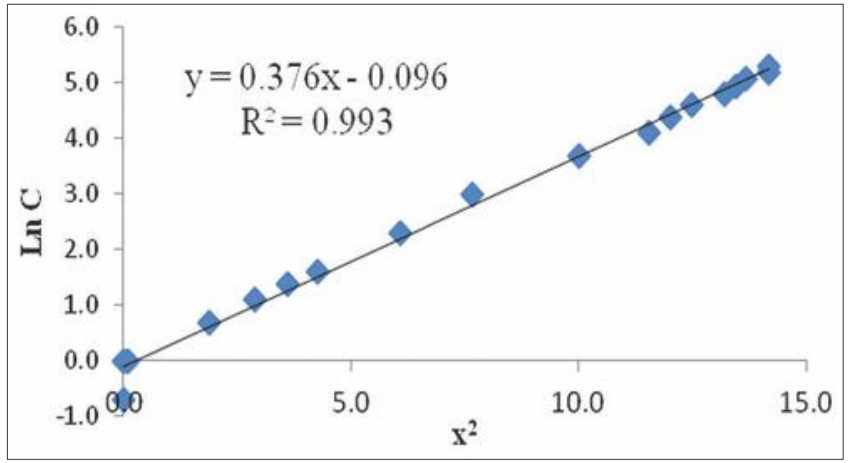

Fig.10: Plot of In C versus $\mathrm{x}^{2}$ of amoxicillin standard solution against Escherichia coli

Antibacterial activities of dissolution aliquot of amoxicillin solid dispersion

The photographs of dissolution aliquots effect on the growth of $S$. aureus and E. coli with agar diffusion method are shown in Figs. 11 and 12 and the data experiment is listed in Table 4. Table 4 shows the antibacterial activities of dissolution aliquots containing amoxicillin-PVP K30 (1:1) solid dispersion which is released from alginate capsule. The dissolution aliquots inhibited the growth of $S$. aureus with ZOI increased from $0.27 \pm 0.03$ to $6.94 \pm 0.48 \mathrm{~mm}$ and inhibited the growth of $E$. coli with ZOI from $0.37 \pm 0.17$ to $6.04 \pm 0.84 \mathrm{~mm}$.

The results showed that the ZOI for $S$. aureus was not much different with ZOI for E. coli. Amoxicillin is a broad-spectrum antibiotic that is effective against bacteria both Gram-negative and Gram-positive bacteria [3]. ZOI of amoxicillin solid dispersion against $S$. aureus and 
Table 3: Antibacterial activities of standard solution of amoxicillin against $S$. aureus and $E$. coli

\begin{tabular}{|c|c|c|c|}
\hline \multicolumn{2}{|c|}{ Concentrations $(\mu \mathrm{g} / \mathrm{mL})(\mathrm{C})$} & \multicolumn{2}{|c|}{ S. aureus } \\
\hline & & $\ln (\mathrm{C})$ & ZOI $(\mathrm{mm})(\mathrm{x})$ \\
\hline \multicolumn{2}{|l|}{0} & 0.000 & 0.000 \\
\hline \multicolumn{2}{|l|}{0,5} & -0.693 & 0.067 \\
\hline \multicolumn{2}{|l|}{1} & 0.000 & 0.167 \\
\hline \multicolumn{2}{|l|}{2} & 0.693 & 1.300 \\
\hline \multicolumn{2}{|l|}{3} & 1.099 & 1.800 \\
\hline \multicolumn{2}{|l|}{4} & 1.386 & 2.267 \\
\hline \multicolumn{2}{|l|}{5} & 1.609 & 2.500 \\
\hline \multicolumn{2}{|l|}{10} & 2.303 & 2.993 \\
\hline \multicolumn{2}{|l|}{20} & 2.996 & 3.367 \\
\hline \multicolumn{2}{|l|}{40} & 3.689 & 3.767 \\
\hline \multicolumn{2}{|l|}{60} & 4.094 & 4.000 \\
\hline \multicolumn{2}{|l|}{80} & 4.382 & 4.133 \\
\hline \multicolumn{2}{|l|}{100} & 4.605 & 4.233 \\
\hline \multicolumn{2}{|l|}{120} & 4.787 & 4.333 \\
\hline \multicolumn{2}{|l|}{140} & 4.942 & 4.433 \\
\hline \multicolumn{2}{|l|}{160} & 5.075 & 4.467 \\
\hline \multicolumn{2}{|l|}{180} & 5.193 & 4.567 \\
\hline \multicolumn{2}{|l|}{200} & 5.298 & 4.533 \\
\hline \multicolumn{4}{|c|}{ ZOI: Zone of inhibition, S. aureus: Staphylococcus aureus, E. coli: Escherichia coli } \\
\hline \multicolumn{4}{|c|}{$\begin{array}{l}\text { Table 4: Antibacterial activities of dissolution aliquot of } \\
\text { amoxicillin solid dispersion }\end{array}$} \\
\hline \multirow[t]{2}{*}{ fime (tirs) } & $201(\mathrm{~mm})$ & & \\
\hline & \multicolumn{2}{|c|}{ Staphylococcus aureus } & Escherichia coli \\
\hline 0 & $0.00 \pm 0.00$ & & $0.00 \pm 0.00$ \\
\hline 0,5 & $0.27 \pm 0.03$ & & $0.37 \pm 0.17$ \\
\hline 1 & $0.80 \pm 0.24$ & & $0.91 \pm 0.32$ \\
\hline 2 & $1.08 \pm 0.30$ & & $1.44 \pm 0.08$ \\
\hline 3 & $1.88 \pm 0.23$ & & $2.01 \pm 0.07$ \\
\hline 4 & $2.48 \pm 0.41$ & & $2.51 \pm 0.18$ \\
\hline 5 & $3.09 \pm 0.70$ & & $3.07 \pm 0.30$ \\
\hline 6 & $3.62 \pm 0.95$ & & $3.71 \pm 0.59$ \\
\hline 7 & $4.11 \pm 0.92$ & & $4.20 \pm 0.75$ \\
\hline 8 & $4.56 \pm 0.92$ & & $4.51 \pm 0.89$ \\
\hline 9 & $5.07 \pm 0.80$ & & $4.88 \pm 0.79$ \\
\hline 10 & $5.62 \pm 0.77$ & & $5.32 \pm 0.96$ \\
\hline 11 & $6.13 \pm 0.63$ & & $5.71 \pm 0.86$ \\
\hline 12 & $6.94 \pm 0.48$ & & $6.04 \pm 0.84$ \\
\hline
\end{tabular}

ZOI: Zone of inhibition

E. coli increased with increasing time of dissolution due to the increase of amoxicillin concentration in the solution.

Correlation of ZOI of aliquot dissolution of amoxicillin solid dispersion with calculated ZOI of standard solution

Calculated ZOI values of standard solution for $S$. aureus are listed in Table 5. Calculated ZOI of standard solution was obtained by inserting the $\ln \mathrm{C}$ values of dissolution aliquot of solid dispersion into the regression equation of the graph of Fig. 9 to obtain the calculated ZOI of standard solution for $S$. aureus. The same method of $\ln C$ values of Table 6 is inserted to the regression equation of the graph of Fig. 10 to obtain the calculated ZOI of standard solution for E. coli. Calculated ZOI values of standard solution for $E$. coli are listed in Table 6 .

The correlation of ZOI of aliquot dissolution of amoxicillin solid dispersion with ZOI of standard solution (calculated) is shown in Fig. 13a for S. aureus and Fig. 13b for E. coli. As shown in Fig. 13, the plot of ZOI of dissolution aliquot of amoxicillin solid dispersion versus ZOI of standard solution (calculated) gives a straight line with $\mathrm{R}^{2}$ is 0.999 . It means that there is a high correlation between ZOI of standard solution and ZOI of dissolution aliquot of amoxicillin solid dispersion. This indicates that the inhibitory effect of amoxicillin standard solution and dissolution aliquot of amoxicillin release from floating alginate capsules is not different against $S$. aureus and E. coli.

\begin{tabular}{|c|c|c|c|}
\hline$x^{2}$ & $\begin{array}{l}\text { E. coli } \\
\text { In (C) }\end{array}$ & $\mathrm{ZOI}(\mathrm{mm})(\mathrm{x})$ & $x^{2}$ \\
\hline 0.000 & 0.000 & 0.000 & 0.000 \\
\hline 0.004 & -0.693 & 0.033 & 0.001 \\
\hline 0.028 & 0.000 & 0.300 & 0.090 \\
\hline 1.690 & 0.693 & 1.367 & 1.868 \\
\hline 3.240 & 1.099 & 1.700 & 2.890 \\
\hline 5.138 & 1.386 & 1.900 & 3.610 \\
\hline 6.250 & 1.609 & 2.067 & 4.271 \\
\hline 8.960 & 2.303 & 2.467 & 6.084 \\
\hline 11.334 & 2.996 & 2.767 & 7.654 \\
\hline 14.188 & 3.689 & 3.167 & 10.028 \\
\hline 16.000 & 4.094 & 3.400 & 11.560 \\
\hline 17.084 & 4.382 & 3.467 & 12.018 \\
\hline 17.921 & 4.605 & 3.533 & 12.484 \\
\hline 18.778 & 4.787 & 3.633 & 13.201 \\
\hline 19.654 & 4.942 & 3.667 & 13.444 \\
\hline 19.951 & 5.075 & 3.700 & 13.690 \\
\hline 20.854 & 5.193 & 3.767 & 14.188 \\
\hline 20.551 & 5.298 & 3.767 & 14.188 \\
\hline
\end{tabular}

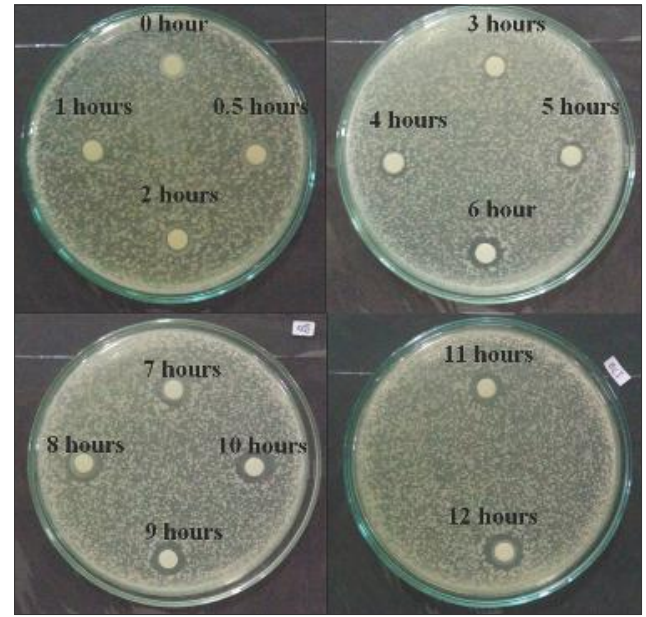

Fig. 11: Zone of inhibition of dissolution aliquot of amoxicillin solid dispersion against Staphylococcus aureus

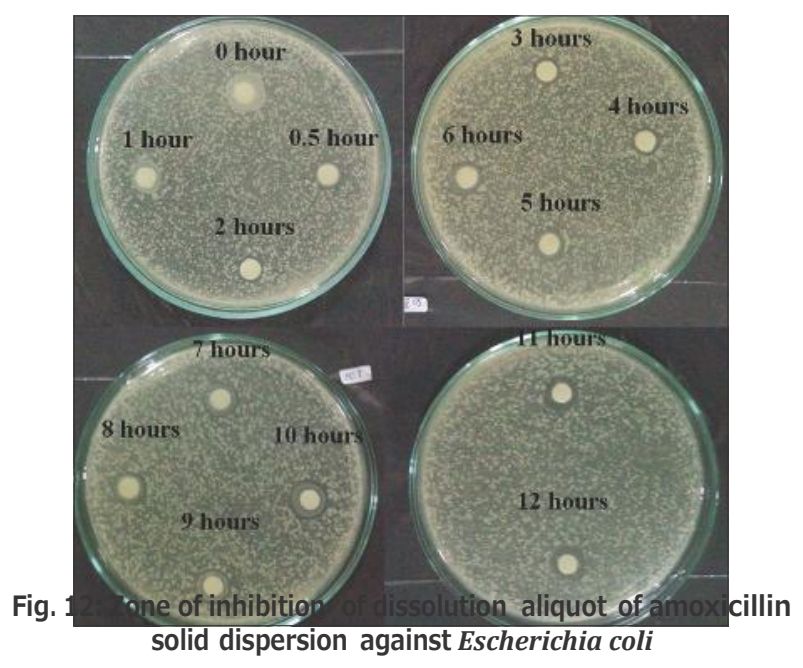

CONCLUSIONS

Hard alginate capsules shell can be used to obtain a sustained release of floating gastroretentive of amoxicillin, but amoxicillin should be used in 
Table 5: ZOI of dissolution aliquot of amoxicillin solid dispersion and standard solution (calculated) against Staphylococcus aureus

\begin{tabular}{|c|c|c|c|c|c|}
\hline \multicolumn{4}{|c|}{ Dissolution aliquot } & \multicolumn{2}{|c|}{ Standard solution (calculated) } \\
\hline Time (hrs) & ZOI (mm) (x) & C & $\ln C(y)$ & $x^{2}$ & $\mathrm{ZOI}(\mathrm{mm})(\mathrm{x})$ \\
\hline $\begin{array}{l}0 \\
0.5\end{array}$ & $\begin{array}{l}0.00 \\
0.27\end{array}$ & $\begin{array}{l}0.982 \\
1.000\end{array}$ & $\begin{array}{l}-0.00 \\
0.00\end{array}$ & $\begin{array}{l}0.00 \\
0.07\end{array}$ & $\begin{array}{l}0.000 \\
0.268\end{array}$ \\
\hline 1 & 0.80 & 1.168 & 0.16 & 0.68 & 0.823 \\
\hline 2 & 1.08 & 1.342 & 0.29 & 1.22 & 1.105 \\
\hline 3 & 1.88 & 2.443 & 0.89 & 3.56 & 1.886 \\
\hline 4 & 2.48 & 4.864 & 1.58 & 6.25 & 2.500 \\
\hline 5 & 3.09 & 12.295 & 2.51 & 9.87 & 3.141 \\
\hline 6 & 3.62 & 32.959 & 3.50 & 13.72 & 3.704 \\
\hline 7 & 4.11 & 85.777 & 4.45 & 17.46 & 4.178 \\
\hline 8 & 4.56 & 230.249 & 5.44 & 21.32 & 4.617 \\
\hline 9 & 5.07 & 783.068 & 6.66 & 26.10 & 5.108 \\
\hline 10 & 5.62 & 3549.524 & 8.17 & 32.00 & 5.657 \\
\hline 11 & 6.13 & 16004.215 & 9.68 & 37.89 & 6.155 \\
\hline 12 & 6.94 & 235007.995 & 12.37 & 48.38 & 6.955 \\
\hline
\end{tabular}

ZOI: Zone of inhibition

Tabel 6: ZOI of dissolution aliquot of amoxicillin solid dispersion and standard solution (calculated) against Escherichia coli

\begin{tabular}{|c|c|c|c|c|c|}
\hline \multicolumn{4}{|c|}{ Dissolution aliquot } & \multicolumn{2}{|c|}{ Standard solution (calculated) } \\
\hline Time (hrs) & $\mathrm{ZOI}(\mathrm{mm})(\mathrm{x})$ & C & $\ln C(y)$ & $x^{2}$ & $\mathrm{ZOI}(\mathrm{mm})(\mathrm{x})$ \\
\hline 0 & 0.00 & 0.000 & -0.000 & 0.00 & 0.000 \\
\hline 0.5 & 0.37 & 0.968 & -0.032 & 0.17 & 0.412 \\
\hline 1 & 0.91 & 1.317 & 0.275 & 0.99 & 0.994 \\
\hline 2 & 1.44 & 2.149 & 0.765 & 2.29 & 1.513 \\
\hline 3 & 2.01 & 4.397 & 1.481 & 4.19 & 2.048 \\
\hline 4 & 2.51 & 10.112 & 2.313 & 6.41 & 2.531 \\
\hline 5 & 3.07 & 32.574 & 3.483 & 9.52 & 3.085 \\
\hline 6 & 3.71 & 180.320 & 5.194 & 14.07 & 3.751 \\
\hline 7 & 4.20 & 814.097 & 6.702 & 18.08 & 4.252 \\
\hline 8 & 4.51 & 2410.204 & 7.787 & 20.97 & 4.578 \\
\hline 9 & 4.88 & 8255.688 & 9.018 & 24.24 & 4.923 \\
\hline 10 & 5.32 & 49642.150 & 10.812 & 29.01 & 5.386 \\
\hline 11 & 5.71 & 236530.185 & 12.373 & 33.16 & 5.758 \\
\hline 12 & 6.04 & 1014802.37 & 13.830 & 37.04 & 6.085 \\
\hline
\end{tabular}

ZOI: Zone of inhibition

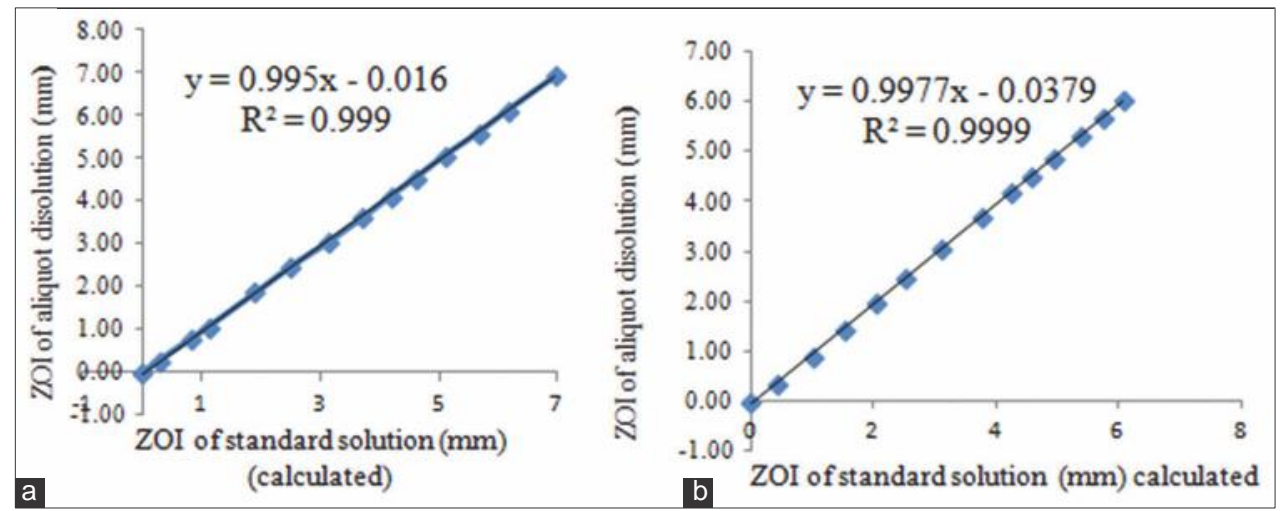

Fig. 13: Correlation plot of zone of inhibition (ZOI) of dissolution aliquot of amoxicillin solid dispersion versus ZOI of standard solution against Staphylococcus aureus (a) and Escherichia coli (b)

the solid dispersion form. The release of pure amoxicillin (without solid dispersion) is too slow. Therefore, amoxicillin should be formulated in the solid dispersion form. Hard alginate capsules containing amoxicillin solid dispersion are immediately float and it float during the dissolution experiment for $12 \mathrm{hrs}$. The dissolution aliquots of amoxicillin solid dispersion inhibit the growth of S. aureus and E. coli.

\section{ACKNOWLEDGMENT}

This research was funded by University Grant (Hibah Unggulan Perguruan Tinggi) 2016 of University of Sumatera Utara.

\section{REFERENCES}

1. Sukandar YE, Andrajati R, Setiadi P, Kusnandar. ISO Pharmacotherapy. Jakarta: PT. ISFI; 2008.

2. Rani AA, Fauzi. Gastric ulcer. In: Sudoyo AW, Setiyohadi B, Alwi I, Simadibrata M, Setiati S, editors. Internal Medicine Text Book. $5^{\text {th }}$ ed. Jakarta: Publisher Center of Internal Medicine; 2009.

3. Kaur SP, Rekha R, Sanju N. Amoxicilin: A broad spectrum antibiotic. Int J Pharm Sci 2011;3(3):30-7.

4. Murakami K, Okimoto T, Kodama M, Sato R, Miyajima H, Ono M, et al. Comparison of amoxicillin-metronidazole plus famotidine or lansoprazole for amoxicillin-clarithromycin-proton pump inhibitor 
treatment failures for Helicobacter pylori infection. Helicobacter 2006;11(5):436-40.

5. Cuna M, Alonso MJ, Torres D. Preparation and in vivo evaluation of mucoadhesive microparticles containing amoxicilli-resin complexes for drug delivery to the gastric mucosa. Eur $\mathrm{J}$ Pharm Biopharm 2001;51(3):199-205.

6. Shah S, Qaqish R, Patel V, Amiji M. Evaluation of the factors influencing stomach-specific delivery of antibacterial agents for Helicobacter pylori infection. J Pharm Pharmacol 1999;51(6):667-72.

7. Bonev B, Hooper J, Parisot J. Principles of assessing bacterial susceptibility to antibiotics using the agar diffusion method. J Antimicrob Chemother 2008;61(6):1295-301.

8. Emara LH, Abdou AR, El-Asmawy AA, Badr RM, Taha NS, Mursi NM. In vitro release evaluation of gastroretentive amoxicillin floating tablets employing a specific design of the flow-through cell. Dissolution Technol 2013;February:27-34

9. Nasa P, Mahant S, Sharma D. Floating systems: A novel approach towards gastroretentive drug delivery systems. Int J Pharm Pharm Sci 2010;2(3):2-7.

10. Gopalakrishnan S, Chenthilnathan A. Floating drug delivery system: A review. J Pharm Sci Technol 2011;3(2):548-54

11. Emara LH, Abdou AR, El-Ashmawy AA, Mursi NM. Preparation and evaluation of metronidazole sustained release floating tablets. Int J Pharm Pharm Sci 2014;6(9):198-204.
12. Draget KI, Smidsrod O, Gudmund S. Alginate from Algae. Weinheim: Wiley Vch Verlag GmbH and Co.; 2005.

13. Aryana, Sinurat D, Ervina I, Bangun H. Formulation of alginate based metronidazole periodontal gel. Asian J Pharm Clin Res 2014;7(1):224-7

14. Mariadi, Bangun H, Karsono. Formulation and in vitro evaluation of gastroretentive drug delivery system of antacids using alginate-chitosan films. Int J PharmTech Res 2015;8(9):1-12.

15. Adliani N, Bangun H, Karsono. Preparation and evaluation of floatingmucoadhesive alginate beads as gastroretentive drug delivery system of antacids. Int J PharmTech Res 2016;9(5):212-22.

16. Bangun H, Simanjuntak MT, Tarigan P, Ismanelly T. Preparation and characterization of gastric resistant alginate capsules. Media Farmasi 2005;13(1):70-9.

17. Murthy KS, Ghebre-Sellassie I. Current perspectives on the dissolution stability of solid oral dosage forms. J Pharm Sci 1993;82:113-26.

18. Bangun H. Preparation, Physical Properties, and Application of Hard Alginate Capsules. Proceeding of International Seminar on Individualized Pharmaceutics for Optimized Drug Delivery, College of Pharmacy, Seoul National University; 2012.

19. Kaewnopparat N, Kaewnopparat S, Jangwang A, Maneenaun D, Chuchome T, Panichayupakaranant P. Increased solubility, dissolution, and physicochemical studies of curcumin-polyvinylpyrrolidine K-30 solid dispersion. World Acad Sci Eng Technol 2009;3:225-30. 